\title{
Stage III Oropharyngeal (p16-Negative) Carcinoma AJCC v8
}

National Cancer Institute

\section{Source}

National Cancer Institute. Stage III Oropharyngeal (p16-Negative) Carcinoma A/CC v8. NCI Thesaurus. Code C132998.

Stage III includes: (T3, N0, M0); (T1, N1, M0); (T2, N1, M0); (T3, N1, M0). T3: Tumor larger than $4 \mathrm{~cm}$ in greatest dimension or extension to lingual surface of epiglottis. T1: Tumor $2 \mathrm{~cm}$ or smaller in greatest dimension. T2: T umor larger than $2 \mathrm{~cm}$ but not larger than $4 \mathrm{~cm}$ in greatest dimension. N0: No regional lymph node metastasis. N1: Tumor with metastasis in a single ipsilateral lymph node, $3 \mathrm{~cm}$ or smaller in greatest dimension and ENE (-). M0: No distant metastasis. (AJCC 8th ed.) 